\title{
Correction to: Slow Release of HIV-1 Protein Nef from Vesicle-like Structures Is Inhibited by Cytosolic Calcium Elevation in Single Human Microglia
}

\author{
Matjaž Stenovec ${ }^{1,2} \cdot$ Eva Lasič $^{2} \cdot$ Pia Pužar Dominkuš $^{3} \cdot$ Saša Trkov Bobnar $^{1,2} \cdot$ Robert Zorec $^{1,2} \cdot$ Metka Lenassi $^{3}$. \\ Marko Kreft ${ }^{1,2,4}$ (D)
}

Published online: 23 July 2019

(C) Springer Science+Business Media, LLC, part of Springer Nature 2019

\section{Correction to: Mol Neurobiol (2019) 56:102-118}

https://doi.org/10.1007/s12035-018-1072-2

The original version of this article unfortunately contained a mistake in Author name. In Pia Pužar Dominkuš, "Pužar" should be classified as Familyname.

Publisher's Note Springer Nature remains neutral with regard to jurisdictional claims in published maps and institutional affiliations.

The online version of the original article can be found at https://doi.org/ 10.1007/s12035-018-1072-2

Robert Zorec

robert.zorec@mf.uni-lj.si

$\triangle$ Metka Lenassi

metka.lenassi@mf.uni-lj.si

$\triangle$ Marko Kreft

marko.kreft@mf.uni-lj.si

Matjaž Stenovec

matjaz.stenovec@mf.uni-lj.si

Eva Lasič

eva.lasic@mf.uni-lj.si

Pia Pužar Dominkuš

pia.puzar-dominkus@mf.uni-lj.si
Saša Trkov Bobnar

sasa.trkov@mf.uni-lj.si

1 Celica Biomedical, Tehnološki park 24, 1000 Ljubljana, Slovenia

2 Laboratory of Neuroendocrinology-Molecular Cell Physiology, Institute of Pathophysiology, Faculty of Medicine, University of Ljubljana, Zaloška 4, 1000 Ljubljana, Slovenia

3 Institute of Biochemistry, Faculty of Medicine, University of Ljubljana, Vrazov trg 2, 1000 Ljubljana, Slovenia

4 CPAE, Department of Biology, Biotechnical Faculty, University of Ljubljana, Večna pot 111, 1000 Ljubljana, Slovenia 